\title{
TRAUMA RAQUIMEDULAR
}

\author{
SPINAL CORD INJURIES
}

Helton L. A. Defino

\begin{abstract}
Docente da Disciplina de Ortopedia e Traumatologia da Faculdade de Medicina de Ribeirão Preto da Universidade de São Paulo Correspondência: Disciplina de Ortopedia e Traumatologia - Av. Bandeirantes, 3900 - $11^{\circ}$ andar - Ribeirão Preto - SP - CEP: 14048-900 - Fone: (0xx16) 602-3224/ 633-7559 - Fax (0xx16) 633-0336 - email: hladefin@fmrp.usp.br
\end{abstract}

DEFINO HLA. Trauma raquimedular. Medicina, Ribeirão Preto, 32: 388-400, out./dez. 1999.

RESUMO: O trauma raquimedular é uma lesão que predomina em adultos jovens do sexo masculino e, pelas características da sua etiologia, sua prevenção pode ser muito efetiva, por meio de campanhas de esclarecimentos junto à população e adoção de medidas de segurança individuais ou coletivas.

A abordagem terapêutica do TRM deve ser multidisciplinar, desde o momento do resgate e remoção dos pacientes até a sua fase final de reabilitação.

Até o momento, não existe nenhum tratamento efetivo capaz de restaurar as funções da medula espinhal lesada. O tratamento é realizado para a reabilitação dos pacientes, de modo que todos os esforços devem ser realizados na prevenção desse tipo irreversível de lesão.

UNITERMOS: Traumatismos da Medula Espinhal. Traumatismo da Coluna Vertebral.

\section{INTRODUÇÃO}

A lesão da medula espinhal (LME) ocorre em cerca de 15 a $20 \%$ das fraturas da coluna vertebral e a incidência desse tipo de lesão apresenta variações nos diferentes países. Estima-se que, na Alemanha, ocorram anualmente dezessete (17) casos novos por milhão de habitantes, nos EUA, essa cifra varia de trinta e dois (32) a cinqüenta e dois (52) casos novos anuais por milhão de habitantes e, no Brasil, cerca de quarenta (40) casos novos anuais por milhão de habitantes, perfazendo um total de seis (06) a oito (08) mil casos por ano, cujo custo aproximado é de U\$ $300,000,000,00$ por ano $^{(1,2)}$.

A lesão ocorre, preferencialmente, no sexo masculino, na proporção de 4:1, na faixa etária entre 15 a 40 anos. Acidentes automobilísticos, queda de altura, acidente por mergulho em água rasa e ferimentos por arma de fogo têm sido as principais causas de trauma- tismo raquimedular (TRM). A freqüência dos TRM em decorrência de ferimentos por projéteis de arma de fogo tem aumentado de modo considerável, refletindo o alto nível de violência nos grandes centros, e a relação entre a velocidade dos veículos no momento da colisão e a ocorrência de fraturas da coluna toracolombar foram demonstradas em estudos de perícia técnica, realizados após os acidentes automobilísticos ${ }^{(3)}$.

Em nossa cidade e região, o mergulho em águas rasas representa uma importante causa de TRM, tendo sido observados sessenta e nove (69) casos entre 1989 a 1996, com o predomínio desse tipo de lesão em pessoas jovens do sexo masculino, principalmente durante o verão.

A análise das principais causas de TRM em nossa cidade (acidente automobilístico, queda de altura e mergulho em água rasa) demonstrou que esse tipo de lesão é passível de prevenção e poderia apresentar redução de sua incidência por meio de campanhas pre- 
ventivas e de esclarecimento junto à população, de modo que a iniciativa da Liga do Trauma no tocante à prevenção desses traumatismos deve ser estimulada para que seja um trabalho contínuo e que procure, de modo crescente, atingir de maneira eficiente o maior número possível de pessoas em nossa cidade. Como exemplo da importância do esclarecimento junto à população, podemos citar que a entrevista com doze (12) pacientes vítimas de TRM por mergulho em água rasa revelou que todos desconheciam a possibilidade da ocorrência desse tipo de acidente, bem como de suas consequiências, pois a preocupação em relação ao lazer aquático estava voltada para o afogamento e não para outro tipo de trauma da coluna cervical ${ }^{(4)}$.

A localização anatômica da lesão está diretamente relacionada ao mecanismo de trauma e cerca de $2 / 3$ das lesões medulares estão localizadas no segmento cervical. Lesões da medula na região torácica ocorrem em $10 \%$ das fraturas desse segmento e em $4 \%$ das fraturas da coluna toracolombar ${ }^{(5)}$.

\section{CONSIDERAÇÕES ANATÔMICAS}

A coluna vertebral é formada por trinta e três (33) a trinta e quatro (34) vértebras ( 07 cervicais, 12 torácicas, 05 lombares, 05 sacrais e 04 ou 05 coccígeas). O forame ou conduto vertebral é formado pela parede posterior do corpo vertebral e parede anterior do arco vertebral, e a superposição dos vários forames vertebrais forma o canal raquídeo, que aloja e protege a medula espinhal.

A medula espinhal, nos adultos, possui cerca de $45 \mathrm{~cm}$ e estende-se desde a altura do atlas $(\mathrm{C} 1)$ até a primeira ou segunda vértebra lombar.

A medula espinhal afila-se para formar o cone medular, do qual se estende um filamento delicado, denominado de "filum terminale", que se insere próximo ao primeiro segmento coccígeo. Na parte baixa do canal vertebral, descendem as raízes dos nervos espinhais caudais, que, juntamente com o "filum terminale", formam a cauda eqüina, que tem o seu início no nível de T11 e termina, caudalmente, no nível do terceiro seg- mento sacral, ocupando sozinha o canal vertebral abaixo de L2. (Figura 1)

A medula espinhal está dividida em segmentos e as raízes nervosas que emergem da medula no nível de cada segmento são designadas por algarismos que se referem ao nível de sua saída. Trinta e um pares de nervos espinhais originam-se da medula espinhal (08 cervicais, 12 torácicos, 05 lombares, 05 sacrais e 01 coccígeo). O primeiro par de nervo espinhal emerge entre o occipital e o atlas (C1), de modo que, na coluna cervical, o nervo emerge, cranialmente, junto a sua vértebra correspondente. Somente a partir do primeiro segmento torácico, o nervo espinhal emerge caudal à sua vértebra correspondente.

Cada raiz nervosa recebe informações sensitivas de áreas da pele denominadas de dermátomos e, similarmente, cada raiz nervosa inerva um grupo de músculos denominados de miótomos.

A localização do segmento da medula espinhal não está na mesma altura do segmento ósseo vertebral correspondente; como exemplo, observamos que o segmento medular C8 está localizado no nível entre C6C7 e o segmento medular T12 no nível de T10. (Figura 1)

A medula espinhal é um grande condutor de impulsos nervosos sensitivos e motores entre o cérebro e as demais regiões do corpo. A medula espinhal possui tratos orientados longitudinalmente (substância branca) circundando áreas centrais (substância cinzenta) onde a maioria dos corpos celulares dos neurônios espinhais estão localizados. Ao corte transversal, a substância cinzenta apresenta a forma de $\mathrm{H}$ e pode ser subdividida em corno anterior, lateral e posterior. No corno anterior, estão localizados os corpos celulares dos neurônios motores e visceromotores (aferentes), no corno posterior os neurônios sensitivos (eferentes) e no corno lateral os neurônios do sistema simpático. As fibras motoras, oriundas do corno anterior, juntam-se às fibras sensitivas do corno posterior para formar o nervo espinhal. 
Os tratos da substância branca constituem vias nervosas ascendentes e descendentes, que conduzem impulsos nervosos em direção ao cérebro e de várias partes do cérebro para o resto do corpo (Figura 2). Os tratos mais importantes do ponto de vista clínico são os relatados a seguir.

$$
\begin{array}{lllll}
\mathbf{T} & \mathbf{r} & \mathbf{a} & \mathbf{t} & \mathbf{o}
\end{array}
$$
espinotalâmico ventral transmite impulsos relacionados ao tato. Possui origem na coluna posterior, cruza para o lado oposto na comissura anterior e ascende pelo funículo anterior até o tálamo.

\section{$\begin{array}{lllll}\mathbf{T} & \mathbf{r} & \mathbf{a} & \mathbf{t} & \mathbf{0}\end{array}$} espinotalâmico lateralmedia os impulsos da sensibilidade dolorosa e da temperatura do lado contralateral. Possui, também, origem na coluna posterior, cruza para o lado oposto na comissura anterior e ascende pelo funículo lateral ao tálamo. Clinicamente, pode ser avaliado, beliscandose a pele ou por meio de estímulo com objetos pontiagudos, como agulha ou alfinete.

Trato espinocerebelar ventral e dorsal- relacionados à propriocepção, conduzem impulsos ao cerebelo por meio da medula espinhal.

Fascículos grácil e cuneiforme - localizados na porção posterior da medula espinhal entre o sulco mediano posterior e sulco póstero-lateral, conduzem impulsos proprioceptivos, provenientes de músculos, tendões e articulações, impulsos táteis localização e discriminação, e sensações vibratórias, como as produzidas pelo cabo do diapasão colocado sobre um osso recoberto de pele.

Trato corticoespinhal lateral e trato corticoespinhal ventral - as vias piramidais transmitem o impulso motor para os motoneurônios do corno anterior, por meio do trato corticoespinhal lateral, que cruza para o lado oposto no bulbo, e do trato corticoespinhal ventral, que desce sem cruzar para o lado oposto, na parte anterior da medula espinhal. Controlam a força motora e são testados por meio da contração voluntária ou contração involuntária mediante estímulo doloroso.

\section{FISIOPATOLOGIA}

A transferência de energia cinética para a medula espinhal, o rompimento dos axônios, a lesão das células nervosas e a rotura dos vasos sangüíneos causam a lesão primária da medula espinhal, e, no estágio agudo da lesão (até 08 horas após o trauma), ocorre hemorragia e necrose da substância cinzenta, seguida de edema e hemorragia. Formam-se petéquias hemorrágicas na substância cinzenta, logo no primeiro minuto da LME, que se aglutinam dentro da primeira hora, resultando na necrose central hemorrágica, que pode estender-se para a substância branca nas 04 a 08 horas seguintes, como conseqüência de uma redução geral do fluxo sangüíneo no local da lesão. A seguir, células inflamatórias migram para o local da lesão, acompanhadas de proliferação de células da glia, e, no período de 01 a 04 semanas, ocorre a formação de tecido cicatricial e cistos no interior da medula espinhal.

A redução do fluxo sangüíneo para o segmento lesado da medula espinhal pode ainda ser ocasionado por alteração do canal vertebral, hemorragia, edema ou redução da pressão sistêmica, que conduzem à lesão adicional, denominada de lesão secundária. Essa redução do fluxo sangüíneo pode provocar a morte das células e axônios que não foram inicialmente lesados. 
A separação física dos tratos da medula espinhal, geralmente, não ocorre nos traumatismos não penetrantes da medula espinhal, tendo sido observada separação física dos axônios somente em alguns casos de ferimento por arma de fogo ${ }^{(6)}$. A separação dos axônios é um processo gradual, que ocorre no local da lesão, após alguns dias do traumatismo, sendo o resultado de uma série de eventos patológicos, relacionados à lesão da membrana celular e suas proteínas, e não da separação física imediata do axônio. A interrupção da condução do estímulo nervoso imediatamente após o trauma, provocado pela energia cinética da lesão, pode ser devida a uma despolarização imediata da membrana do axônio, associada à falha de sua repolarização, que ocasiona perda de potássio pelo axônio ${ }^{(7)}$.

A isquemia do sistema nervoso central é caracterizada por um grande influxo de cálcio para as células ${ }^{(8)}$, e reações metabólicas, como falha das mitocôndrias e ativação das fosfolipases, proteases e adenosina trifosfatase ocorrem, e o resultado é a perda de energia e colapso da membrana celular, que também é mediado pela produção de radicais livres e ativação das fosfolipases e lipases. A impossibilidade da célula em converter completamente o oxigênio para dióxido de carbono e água, promove a formação de radicais livres, que resulta em peroxidação lipídica e subseqüente falha da membrana celular. Esses eventos justificam a utilização da metilprednisolona nas primeiras 08 horas após o TRM, que é administrada com o objetivo de inibir a peroxidação lipídica ${ }^{(9)}$.

\section{AVAliaÇÃo CLÍNiCA}

$\mathrm{O}$ atendimento do paciente no local do acidente é de grande importância para a sua avaliação inicial, reconhecimento de suas lesões e prevenção de lesões adicionais durante o seu resgate e transporte para o local onde deverá receber o atendimento definitivo. Devem ser sempre consideradas a presença de uma lesão da coluna vertebral e a manutenção da imobilização do paciente até que esse tipo de lesão possa ser avaliado com segurança por meio de radiografias e outros exames complementares, quando necessários. As lesões instáveis da coluna vertebral sem lesão neurológica, principalmente em pacientes politraumatizados, vítimas de colisões em alta velocidade, inconscientes ou alcoolizados, possuem grande potencial de lesão adicional das estruturas nervosas durante o resgate e transporte dos pacientes, existindo inú- meros exemplos clínicos de pacientes com quadro neurológico normal após o acidente, e que sofreram lesão das estruturas nervosas durante o resgate e transporte. Em pacientes inconscientes e vítimas de colisão de automóveis ou quedas, a possibilidade da coluna cervical estar lesada é de 5 a $10 \%$ e observouse, no estudo de trezentos (300) pacientes portadores de fratura da coluna cervical, que cerca de $1 / 3$ das fraturas não foram diagnosticadas no momento do atendimento inicial ${ }^{(10)}$.

A avaliação do paciente compreende a história, exame físico, exame neurológico e exame radiológico.

A história do trauma e informações acerca do estado geral do paciente previamente ao trauma são de grande utilidade para auxiliar no esclarecimento do mecanismo de trauma e suas possíveis lesões associadas. A presença de traumatismo cranioencefálico, intoxicação alcoólica, lesões múltiplas, traumas da face e acima da clavícula aumentam a probabilidade da ocorrência de fratura da coluna vertebral.

O exame físico geral do paciente inicia-se pela avaliação de suas vias aéreas "com o controle da coluna cervical", da sua respiração e ventilação, e da circulação $(\mathrm{ABC})$, pois a prioridade, no atendimento inicial, deve ser para a avaliação, preservação e tratamento das funções vitais básicas.

Os pacientes com fratura da coluna vertebral sem lesão neurológica apresentam dor local, que pode irradiar-se para os membros, e incapacidade funcional, acompanhada de espasmo da musculatura adjacente. Nos pacientes com lesão medular, podem ser observadas respiração diafragmática, perda da resposta ao estímulo doloroso, incapacidade de realizar movimentos voluntários nos membros, alterações do controle dos esfíncteres, priapismo e presença de reflexos patológicos (Babinski, Oppenheim), indicando lesão do neurônio motor superior. Os pacientes com lesão medular podem apresentar, também, queda da pressão arterial, acompanhada de bradicardia, que caracteriza o denominado choque neurogênico. Nesses pacientes, a lesão das vias eferentes do sistema nervoso simpático medular e conseqüiente vasodilatação dos vasos viscerais e das extremidades, associadas à perda do tônus simpático cardíaco, não permitem que o paciente consiga elevar a freqüência cardíaca. Essa situação deve ser reconhecida e diferenciada do choque hipovolêmico, no qual a pressão arterial está diminuída e acompanhada de taquicardia. A reposição de líquidos deve ser evitada no choque neurogênico, para não sobrecarregar a volemia. 
O exame neurológico consiste na avaliação da sensibilidade, da função motora e dos reflexos. A área de sensibilidade do paciente é examinada no sentido craniocaudal, desde a região cervical, pela avaliação da sensibilidade à variação de temperatura, sensibilidade dolorosa e sensibilidade tátil, que são funções mediadas pelo trato espinotalâmico lateral, cujas fibras estão na porção anterolateral da medula espinhal. A avaliação da vibração por meio de diapasão ou da posição espacial dos membros avalia as condições do trato posterior da medula espinhal (funículo grácil e cuneiforme).

A distribuição dos dermátomos está ilustrada na Figura 3 e algumas regiões anatômicas possuem relação com esses dermátomos e importância semiológica, como os mamilos (T4), processo xifóide (T7), umbigo (T10), região inguinal (T12-L1) e região perineal (S2S3-S4). (Figura 4)

A avaliação da função motora tem como objetivo a determinação do grau de movimento que o paci-

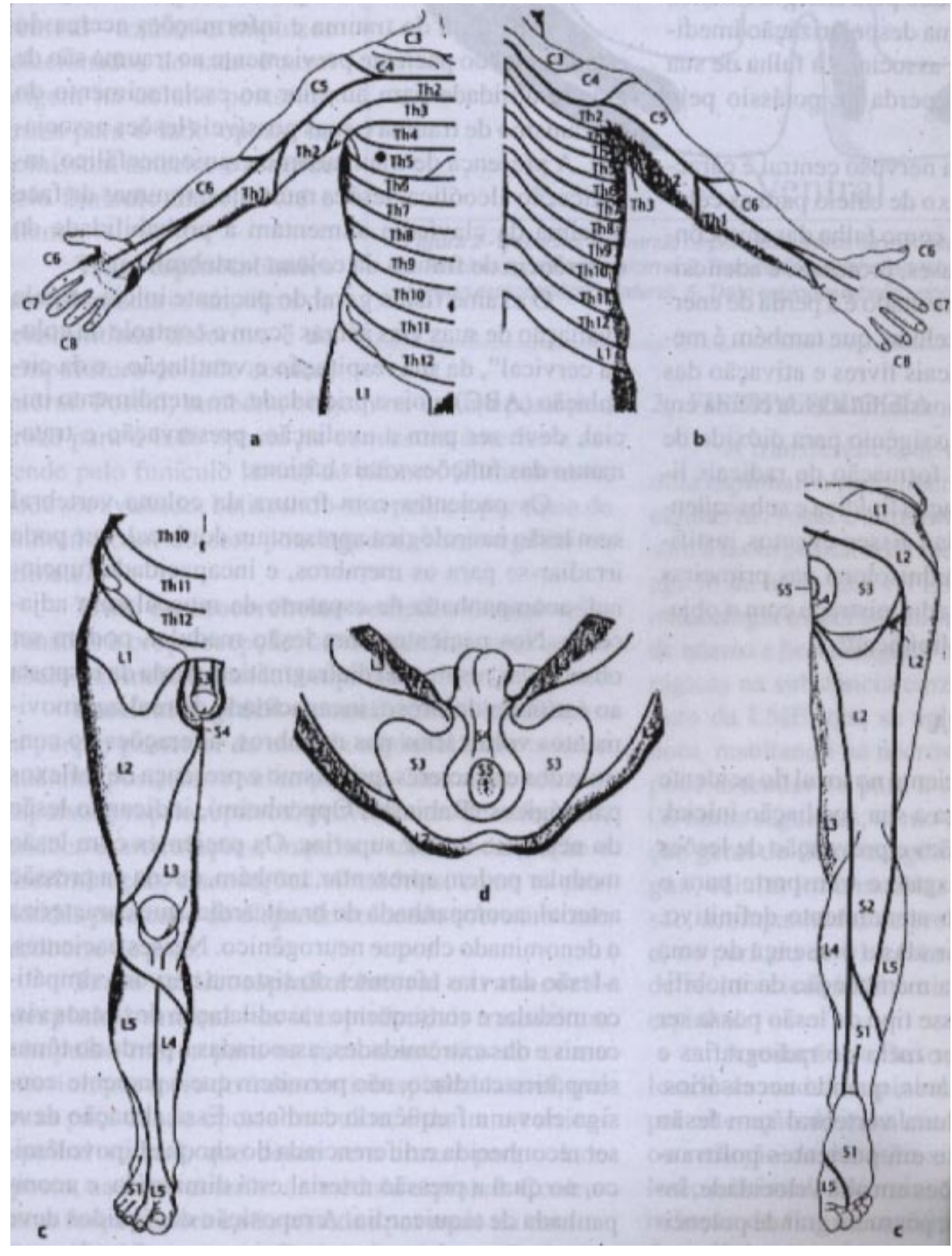

Figura 3 - Distribuição dos dermátomos do membro superior, membro inferior e região perineal. ente possui, avalia a função dos tratos corticoespinhais, sendo insuficiente a constatação apenas da presença ou ausência do movimento nas extremidades, que deve ser quantificado com relação ao grau de força muscular, que é determinada por meio de uma escala que varia de 0 a 5. A paralisia total é considerada 0 ; a presença de contração muscular palpável ou visível, 1 ; a presença de movimento ativo, mas que não vence a força da gravidade, 2 ; movimento ativo que vence a força da gravidade, 3 ; movimento ativo que vence alguma resistência, 4 e movimento ativo normal, 5 .

Deve ser lembrado que as raízes inervam mais de um músculo e que os músculos, geralmente, recebem fibras nervosas de mais de uma raiz nervosa.

Os reflexos tendinosos profundos são mediados pelas células do corno anterior da medula espinhal, e o 


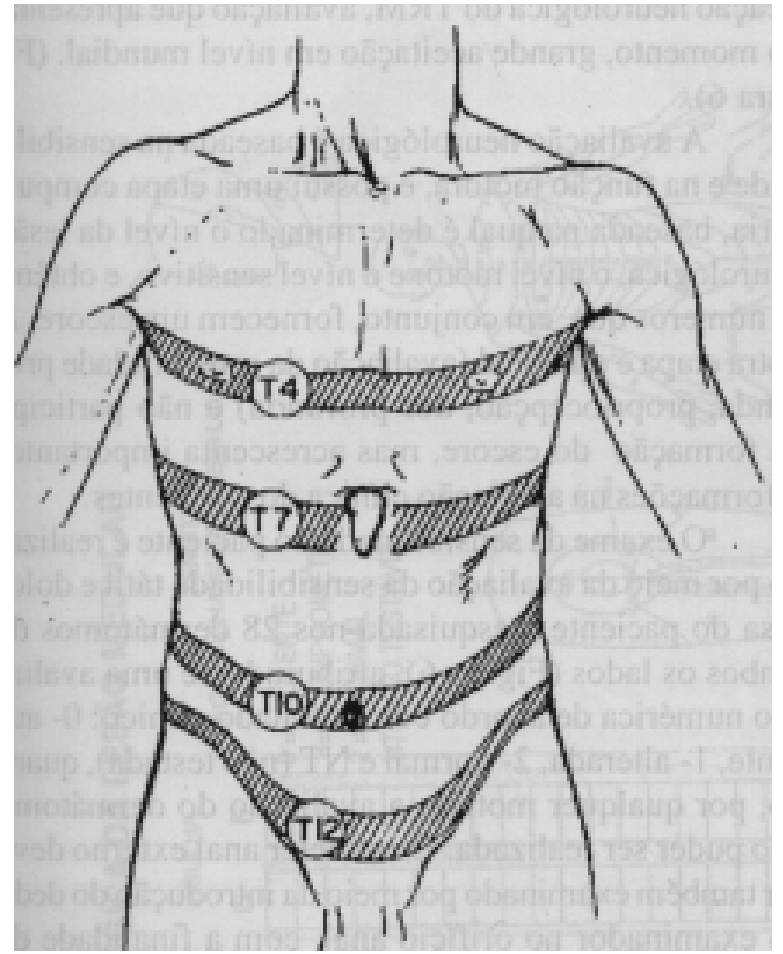

Figura 4 - Desenho, ilustrando a relação entre áreas anatômicas de importância semiológica e seus respectivos dermátomos. a lesão medular não seja completa e permanente, e, nessa situação, o paciente apresenta ausência total da sensibilidade, dos seus movimentos e do reflexo bulbocarvenoso, que, normalmente, está presente. O retorno desse reflexo, que pode ser obtido por meio da estimulação do pênis ou clitóris, provocando contração do esfíncter anal, indica o término do choque medular, permitindo, então, a determinação do déficit neurológico após a lesão. (Figura 5)

A avaliação clínica dos pacientes determina o nível de lesão neurológica, que é considerada como sendo o segmento mais caudal da medula espinhal que apresenta as funções sensitivas e motoras normais de ambos os lados. Quando o termo nível sensitivo é utilizado, refere-se ao nível mais caudal da medula espinhal, que apresenta sensibilidade normal, podendo, do mesmo modo, ser definido o nível motor. O nível esquelético da lesão é determinado por meio de radiografias e corresponde à vértebra lesionada.

A lesão medular é denominada completa, quando existe ausência de sensibilidade e função motora nos segmentos sacrais baixos da medula espinhal, e incompleta nas situações em que é observada preservação parcial das funções motoras abaixo do nível neurológico e inclui os segmentos sacrais baixos da medula espinhal. córtex cerebral exerce uma ação inibidora para evitar a sua resposta exacerbada aos estímulos recebidos. A ausência desse reflexo pode indicar uma lesão do nervo periférico, interrompendo o arco reflexo, ou a presença de choque medular. Os reflexos tendinosos profundos, de maior importância clínica são os reflexos: bicipital (C5), estiloradial (C6), tricipital (C7), patelar (L4) e aquileo (S1).

Os reflexos abdominais e cremastéricos são testes do neurônio motor superior, e a ausência desses reflexos indica lesão do neurônio motor superior, enquanto a perda assimétrica sugere lesão no neurônio motor inferior. As lesões do neurônio motor superior podem também ser diagnosticadas pela presença de reflexos patológicos, evidenciados pelo teste de Babinski ou Oppenheim.

O reflexo bulbocavernoso é de grande importância na avaliação dos pacientes com TRM, que apresentam choque medular. O choque medular pode ocorrer imediatamente após o traumatismo da medula espinhal, mesmo que

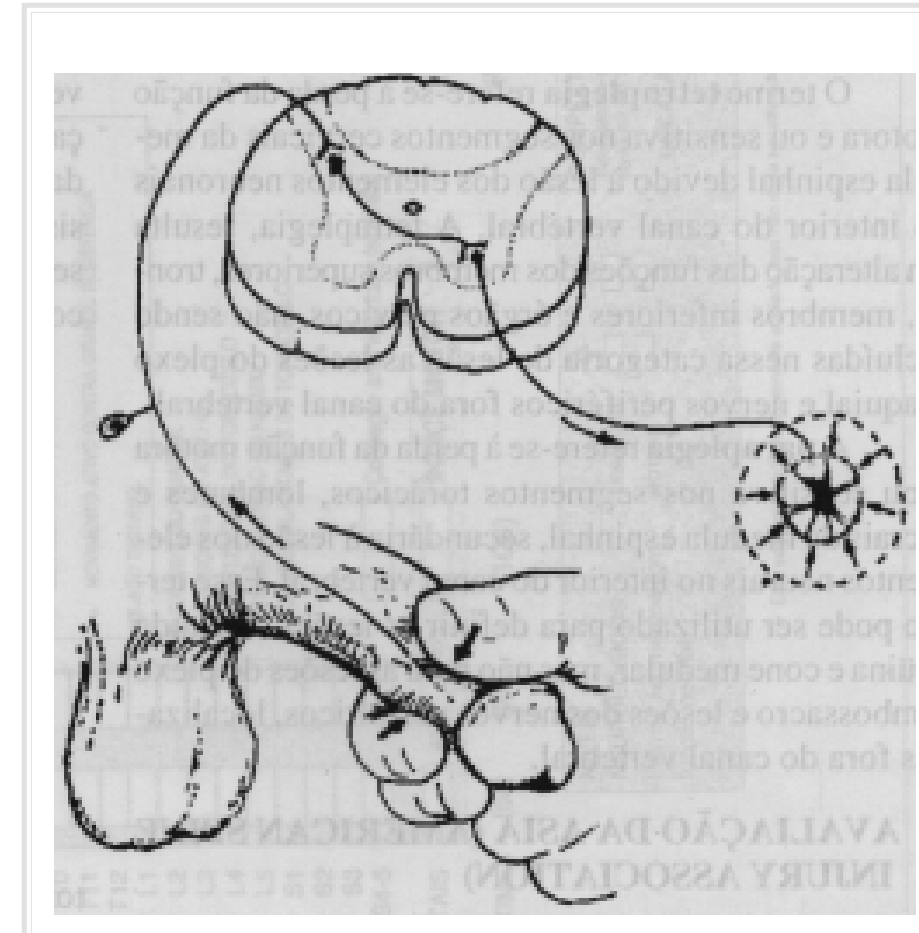

Figura 5 - Desenho, ilustrando o reflexo bulbocavernoso e sua avaliação no sexo masculino. 
Algumas síndromes medulares têm sido descritas e elas apresentam quadro neurológico característico, dependendo da localização da lesão no interior da medula espinhal. A síndrome da medula central ocorre, principalmente, na região cervical e apresenta comprometimento mais acentuado dos membros superiores que dos membros inferiores. Na síndrome da medula anterior, existe preservação da propriocepção e perda variável da função motora e da sensibilidade à dor. Na síndrome de Brown-Séquard, a hemisecção da medula ocasiona perda da função motora e proprioceptiva do lado da lesão e perda da sensibilidade à dor e temperatura do lado oposto. Na síndrome da medula posterior, a função motora, a sensibilidade à dor e tato estão preservados, enquanto que a propriocepção está alterada. A lesão da medula espinhal no nível sacral, geralmente no nível ósseo de T12-L1 (síndrome do cone medular), resulta em incontinência fecal, vesical e alteração da função sexual. A sensibilidade está alterada nos 03 a 04 segmentos sacrais distais e segmentos coccígeos (anestesia em cela) e o reflexo bulbo cavernoso encontra-se ausente. A lesão isolada dos nervos espinhais da cauda eqüina (lesão da cauda equiina) no interior do canal vertebral, geralmente, ocorre nas fraturas distais a L1-L2, e, na verdade, não são lesões da medula espinhal. O quadro clínico depende da raiz atingida e podem ser observados paresia do membro inferior, arreflexia, distúrbios da sensibilidade e, também, incontinência fecal e vesical.

$\mathrm{O}$ termo tetraplegia refere-se à perda da função motora e ou sensitiva nos segmentos cervicais da medula espinhal devido à lesão dos elementos neuronais no interior do canal vertebral. A tetraplegia, resulta em alteração das funções dos membros superiores, tronco, membros inferiores e órgãos pélvicos, não sendo incluídas nessa categoria de lesão as lesões do plexo braquial e nervos periféricos fora do canal vertebral.

A paraplegia refere-se à perda da função motora e ou sensitiva nos segmentos torácicos, lombares e sacrais da medula espinhal, secundária à lesão dos elementos neurais no interior do canal vertebral. Esse termo pode ser utilizado para definir as lesões da cauda eqüina e cone medular, mas não para as lesões do plexo lombossacro e lesões dos nervos periféricos, localizadas fora do canal vertebral.

\section{AVALIAÇÃO DA ASIA (AMERICAN SPINE INJURY ASSOCIATION)}

A Associação Americana do Trauma Raquimedular (ASIA- American Spine Injury Association) desenvolveu, em 1992, padrões para a avaliação e clas- sificação neurológica do TRM, avaliação que apresenta, no momento, grande aceitação em nível mundial. (Figura 6).

A avaliação neurológica é baseada na sensibilidade e na função motora, e possui uma etapa compulsória, baseada na qual é determinado o nível da lesão neurológica, o nível motor e o nível sensitivo, e obtêmse números que, em conjunto, fornecem um escore. A outra etapa é opcional (avaliação da sensibilidade profunda, propriocepção, dor profunda) e não participa na formação do escore, mas acrescenta importantes informações na avaliação clínica dos pacientes.

O exame da sensibilidade do paciente é realizado por meio da avaliação da sensibilidade tátil e dolorosa do paciente, pesquisada nos 28 dermátomos de ambos os lados (Figura 6), atribuindo-se uma avaliação numérica de acordo com o achado clínico: 0- ausente, 1- alterada, 2- normal e NT (não testada), quando, por qualquer motivo, a avaliação do dermátomo não puder ser realizada. O esfíncter anal externo deve ser também examinado por meio da introdução do dedo do examinador no orifício anal, com a finalidade de determinar-se se a lesão é completa ou incompleta (sensibilidade presente-sim, ou ausente-não).

A avaliação da função motora é realizada por meio da avaliação de ambos os lados, de músculos denominados "músculos chaves" em 10 pares de miótomos, e a força muscular graduada de acordo com a seguinte escala: 0- paralisia toral, 1- contração palpável ou visível, 2- movimento ativo eliminado pela força da gravidade, 3-movimento ativo que vence a força da gravidade, 4- movimento ativo contra alguma resistência, 5- normal e NT (não testada).Os músculos selecionados para a avaliação e os níveis neurológicos correspondentes são:

C5- flexores do cotovelo

C6- flexores do punho

C7- extensores do cotovelo

C8- flexores do dedo (falanges média e distal)

T1- abdutores (dedo mínimo)

L2- flexores do quadril

L3- flexores do joelho

L4- dorsiflexores do tornozelo

L5- extensor longo dos dedos

S1- flexores plantares do tornozelo

Adicionalmente ao exame dos 10 pares de miótomos mencionados, o esfíncter anal externo deve ser também examinado para se avaliar a sua capacidade de contração voluntária ( diferenciação da lesão incompleta ou completa. 


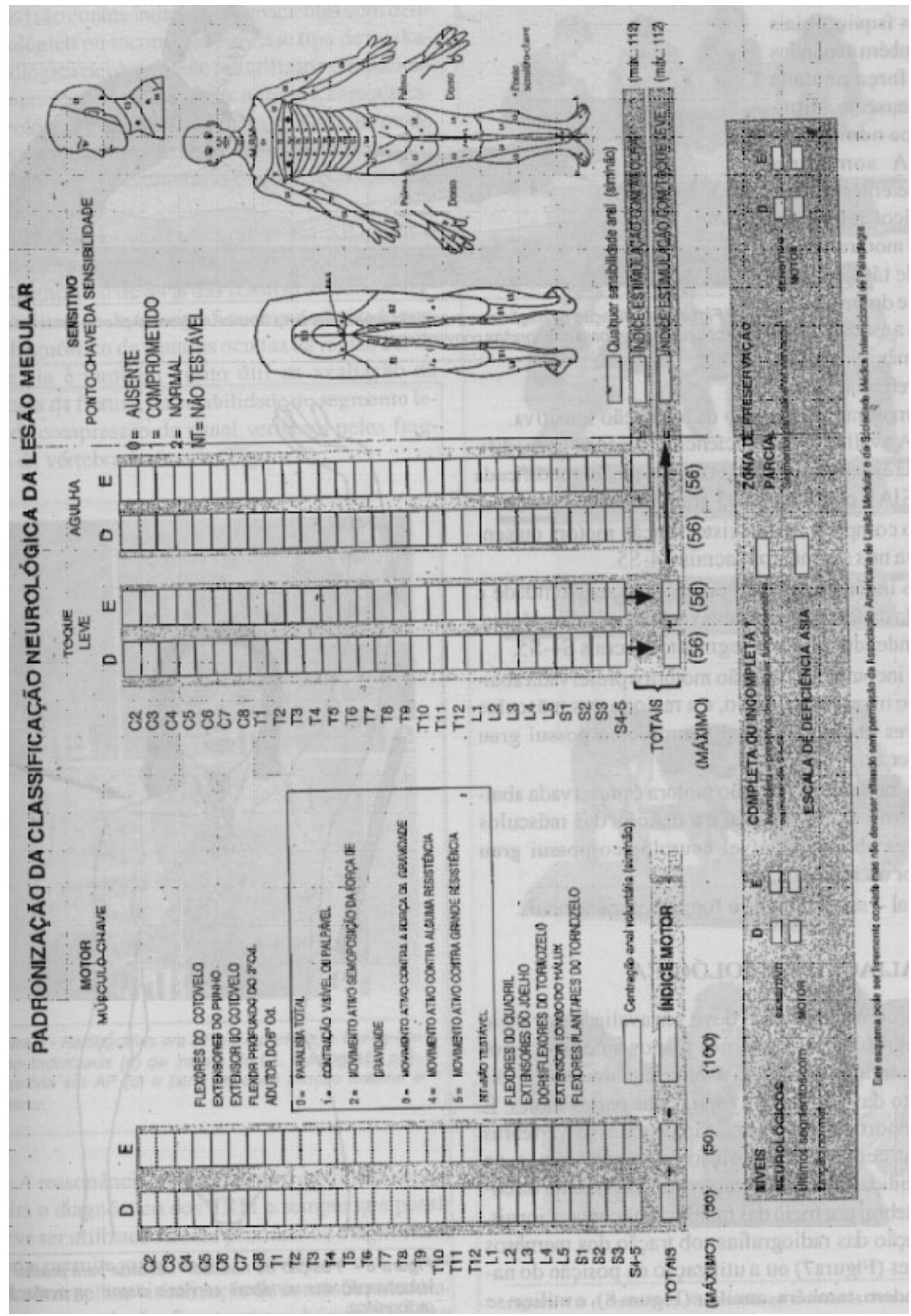

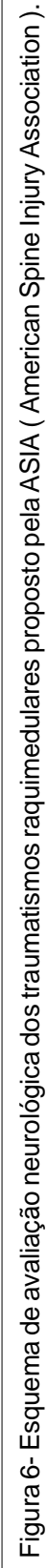


Opcionalmente, o diafragma, o deltóide e os ísquio tibiais são também avaliados e sua força anotada como ausente, diminuída ou normal.

A somatória dos diferentes valores numéricos referentes à força motora, sensibilidade tátil e sensibilidade dolorosa dão origem a escores, cujo valor máximo é 100 para o referente à

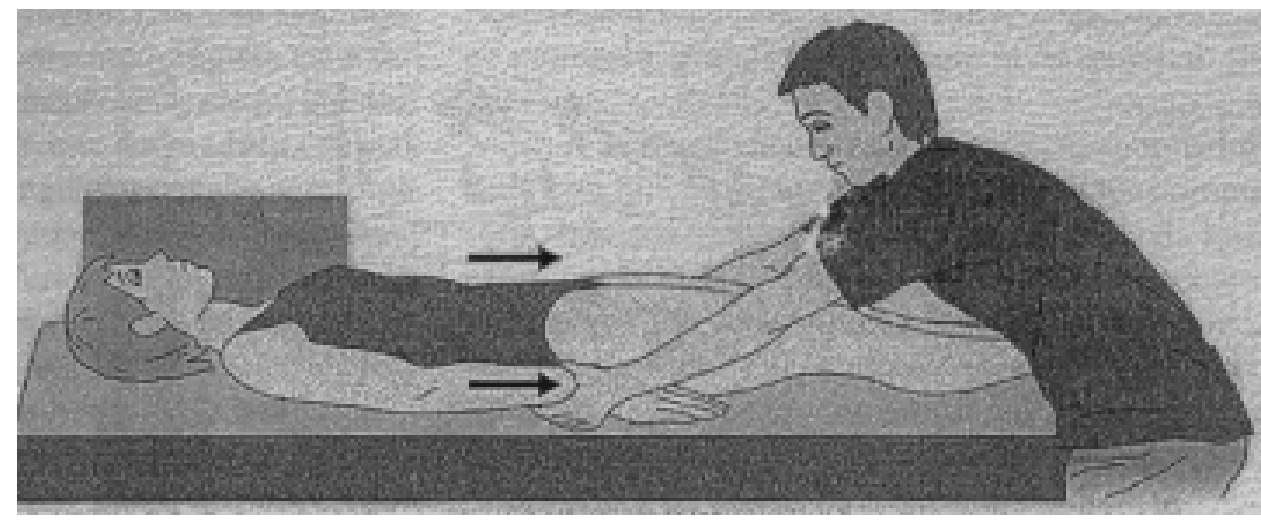

Figura 7- Aplicação de tração nos membros superiores para auxiliar a visualização da parte baixa da coluna cervical para radiografias convencionais.

avaliação motora e 112 para o da avaliação sensitiva.

A avaliação da deficiência é baseada na modificação da escala de Frankel et al. ${ }^{(11)}$, que foi modificada pela ASIA e consiste em 05 graus de incapacidade:

a) lesão completa - não existe função motora ou sensitiva nos segmentos sacrais S4-S5.

c) lesão incompleta - preservação da sensibilidade e perda da força motora abaixo do nível neurológico, estendendo-se até os segmentos sacrais S4-S5.

c) lesão incompleta - função motora é preservada abaixo do nível neurológico, e a maioria dos músculos chaves abaixo do nível neurológico possui grau menor ou igual a 3 .

d) lesão incompleta - função motora é preservada abaixo do nível neurológico e a maioria dos músculos chaves abaixo do nível neurológico possui grau maior ou igual a 3 .

e) normal - sensibilidade e força motora normais.

\section{AVALIAÇÃO RADIOLÓGICA}

A coluna vertebral deve ser avaliada por meio de radiografias realizadas nos planos anteroposterior (AP) e lateral, procurando avaliar a assimetria, o alinhamento das vértebras e roturas das partes moles. É muito importante a visualização de todas as vértebras da coluna cervical e a transição cervicotorácica, e, na impossibilidade da visualização desse segmento da coluna vertebral por meio das radiografias convencionais, a realização das radiografias sob tração dos membros superiores (Figura7) ou a utilização da posição do nadador podem, também, auxiliar (Figura 8), e utiliza-se a tomografia computadorizada nas situações extremas.

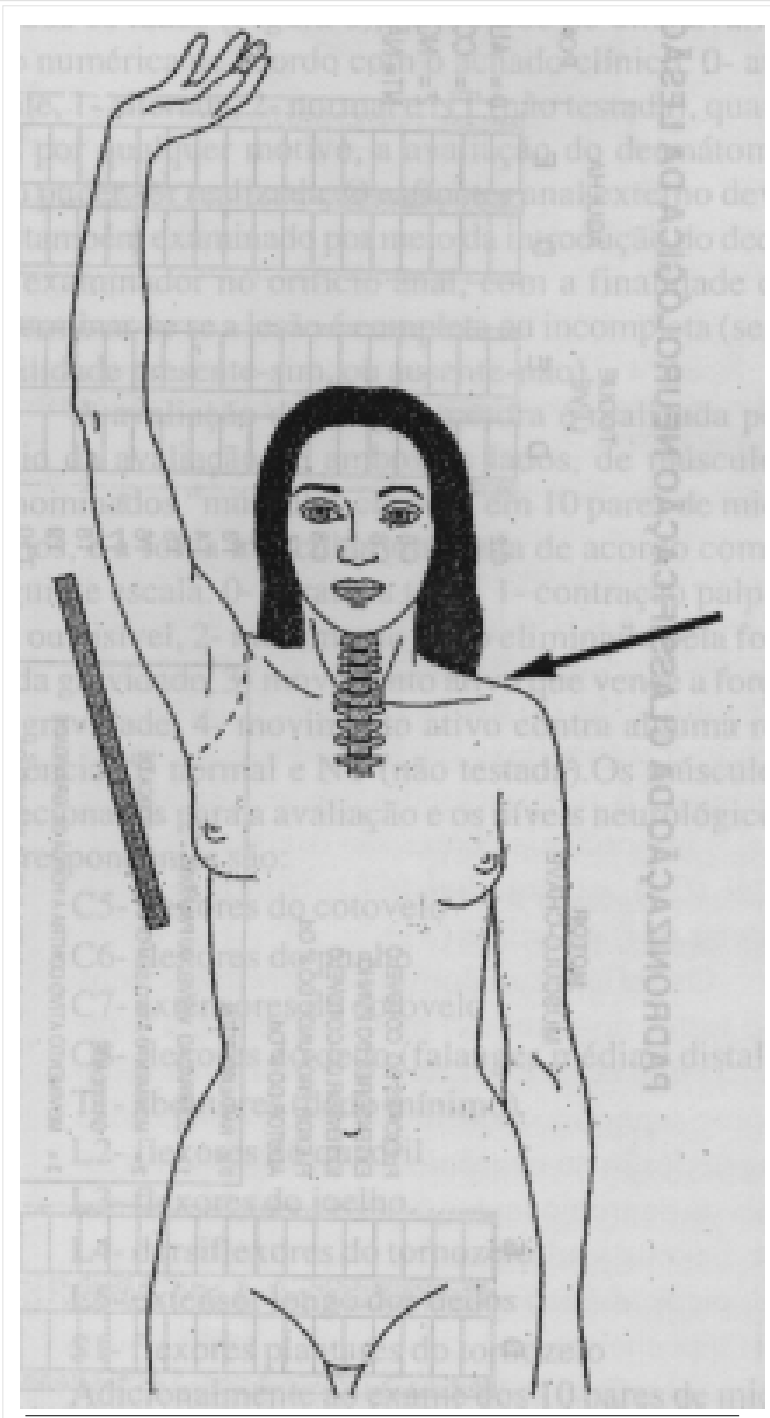

Figura 8 - "Posição do nadador" utilizada para auxiliar a visualização das vértebras cervicais distais na avaliação radiográfica. 
As radiografias dinâmicas (hiperflexão e hiperextensão) são contra-indicadas em pacientes com déficit neurológico ou inconscientes. Esse tipo de avaliação radiológica deve somente ser utilizada em pacientes que apresentem radiografias normais, sem alteração neurológica e em perfeito estado de alerta, de modo que possam realizar a flexão e extensão ativa da coluna cervical de modo voluntário e com o total controle da situação.

A realização das radiografias em AP, perfil e transoral para a observação do processo odontóide permite o diagnóstico de $84 \%$ das fraturas da coluna cervical. A utilização da tomografia computadorizada permite o diagnóstico de fraturas ocultas da região cervical $^{(12)}$ e ela é também muito útil na avaliação da morfologia da fratura, da estabilidade do segmento lesado e da compressão do canal vertebral pelos fragmentos da vértebra fraturada.(Figura 9).

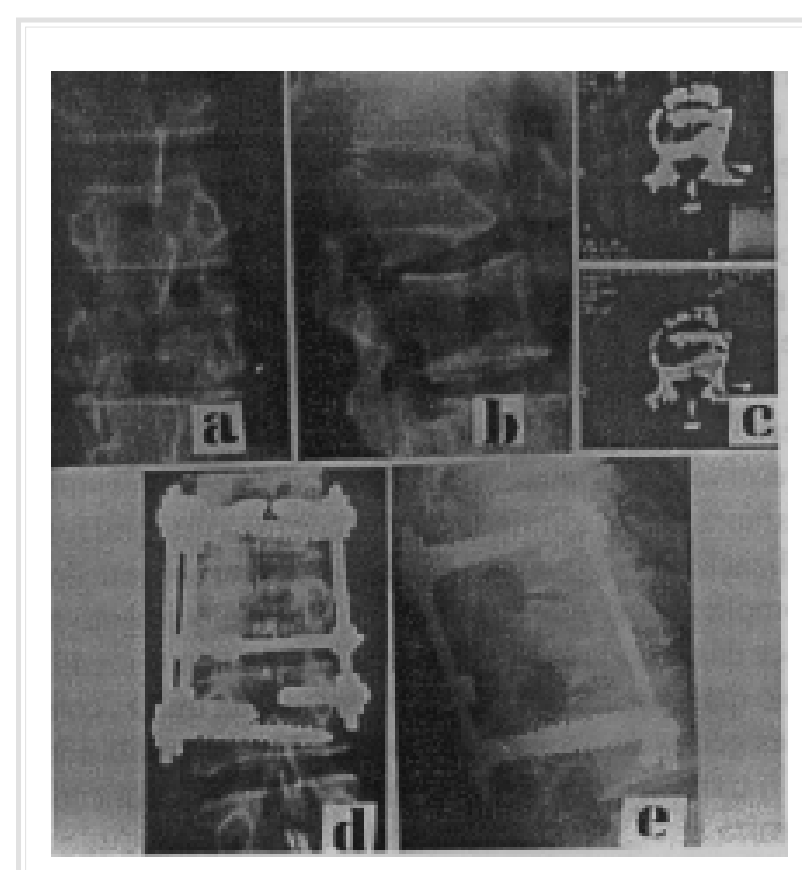

Figura 9 - Radiografias em AP (a) e perfil (b) e tomografia computadorizada (c) de fratura de L1. Radiografia pósoperatória em AP (d) e perfil (e) após fixação anterior e posterior.

A ressonância magnética tem auxiliado sobremaneira o diagnóstico dos TRM e sempre que possível deve ser utilizada na fase primária do diagnóstico, pois ela permite uma análise detalhada das partes moles, com melhor visualização de contusões medulares, hematomas, lesões ligamentares, hérnias discais e coleções líquidas.

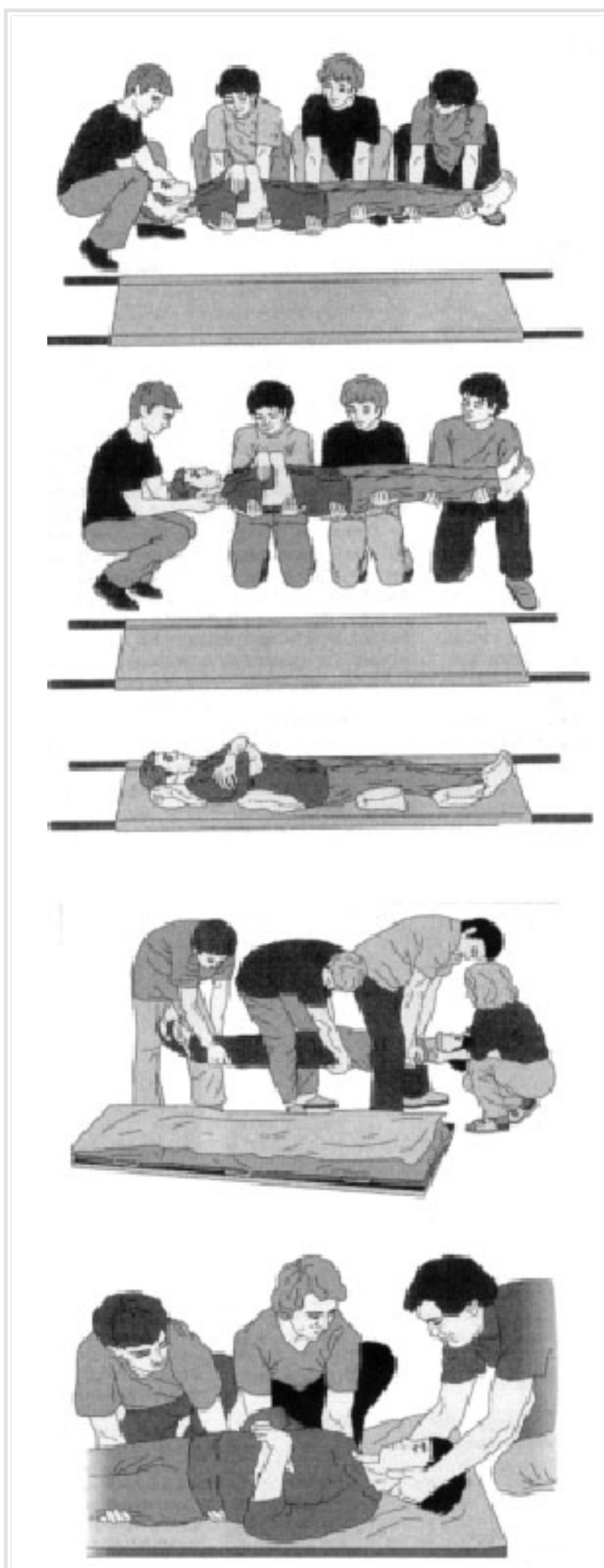

Figura 10 - Desenho, ilustrando os cuidados iniciais na remoção e transporte dos pacientes. 


\section{TRATAMENTO}

O tratamento dos TRM deve ter início no momento do atendimento inicial, ainda fora do ambiente hospitalar, durante o resgate e transporte dos pacientes, com o objetivo de evitar lesões adicionais ou ampliação das lesões já existentes. A imobilização da coluna cervical deve ser realizada em todos os pacientes politraumatizados e retirada somente após a confirmação da ausência de lesão. Cuidados especiais devem ser tomados durante o transporte dos pacientes e durante a retirada de capacetes de ciclistas ou motociclistas vítimas de acidente. (Figuras 10 e 11)

$\mathrm{O}$ tratamento na emergência tem como principal objetivo a manutenção e o restabelecimento das funções vitais do paciente (ABC - vias aéreas, respiração e circulação), de modo que o tratamento específico da lesão do segmento vertebral com lesão medular é realizada somente após a resolução dessa fase. É importante lembrar a ocorrência do choque neurogênico (hipotensão associada à bradicardia) nos pacientes com lesão acima de T6 para evitar-se a administração de líquidos e conseqüente sobrecarga hídrica.

A metil prednisolona tem sido administrada até 08 horas após a lesão da medula espinhal, com base nos resultados observados no NASCIS I e II (National Spinal Cord Injury Study), realizados em 1990 e 1992, nos quais foi observada uma melhora neurológica significativa no grupo de pacientes em que essa droga foi administrada. A metil prednisolona tem a capacidade de reduzir a peroxidação lipídica e preservar a integridade das estruturas neuronais, atuando no nível da lesão secundária devido à isquemia e ação dos radicais livres. A metil- prednisolona possui maior efeito que a dexametasona na inibição da peroxidação lipídica, e outras drogas, como o mesilato de tiralazade, que é da classe dos compostos conhecidos como 21-aminoesteróides ou lazaróides, têm sido também utilizadas, pois, também, são potentes inibidores da peroxidação lipídica e não apresentam os efeitos colaterais dos corticóides.

A dose recomendada de metil-prednisolona é de $30 \mathrm{mg} / \mathrm{Kg}$ de peso, administrada em bolo durante 15 minutos, e 45 minutos após essa dose em bolo, administram-se $5,4 \mathrm{mg} / \mathrm{Kg}$ em infusão constante por 23 horas. A dose total de metil-prednisolona é de 154,2 $\mathrm{mg} / \mathrm{Kg}$ de peso em 24 horas, e deve ser administrada

nas primeiras 08 horas após o trauma. Após esse período, a administração dessa droga não alcança o objetivo desejado e pode acarretar ainda certos efeitos nocivos. A utilização dessas drogas, disseminada principalmente nos EUA, tem sido objeto de críticas em outros países e não há consenso definitivo sobre o papel protetor delas, nos traumatismos raquimedulares.

O tratamento definitivo da lesão, no segmento vertebral fraturado, tem, como principais objetivos, a preservação da anatomia e função da medula espinhal, restauração do alinhamento da coluna vertebral, estabilização do segmento vertebral lesado, prevenção de complicações gerais e locais, e o restabelecimento precoce das atividades dos pacientes, devendo ser realizado o mais precocemente possível, desde que as condições gerais do paciente permitam. Na impossibilidade de o tratamento definitivo ser realizado, a redução da fratura e realinhamento do canal vertebral deve ser realizado por meio de tração.

Não existe até o momento nenhum tratamento cirúrgico capaz de restaurar as funções da medula espinhal lesada e o objetivo do tratamento cirúrgico é apenas a redução e o realinhamento do segmento vertebral lesado, restauração da estabilidade do segmento lesado, de modo a evitar lesões adicionais da medula espinhal e favorecer a sua recuperação. Outra vantagem adicional dos modernos métodos de fixação vertebral é a possibilidade da mobilização precoce dos pacientes, sem a utilização de imobilização externa, o que facilita a reabilitação no período pós-operatório (Figuras 9, 12 e 13). 
As indicações do tratamento cirúrgico têm sido baseadas na presença de instabilidade do segmento vertebral e lesão neurológica, existindo controvérsia com relação a esse tópico. A presença de paralisia após intervalo de quadro neurológico normal, presença de paralisia rápida e progressiva ou paralisia incompleta, que evolui para paralisia completa, têm sido consideradas como indicações absolutas e urgentes de tratamento cirúrgico.

Nossa conduta atual tem sido no sentido de realizar a estabilização precoce das lesões, para facilitar a mobilização precoce dos pacientes e promover de modo mais rápido sua reabilitação e reintegração social e não no sentido de realizar sua recuperação neurológica, uma vez que o papel da descompressão é muito discutível.
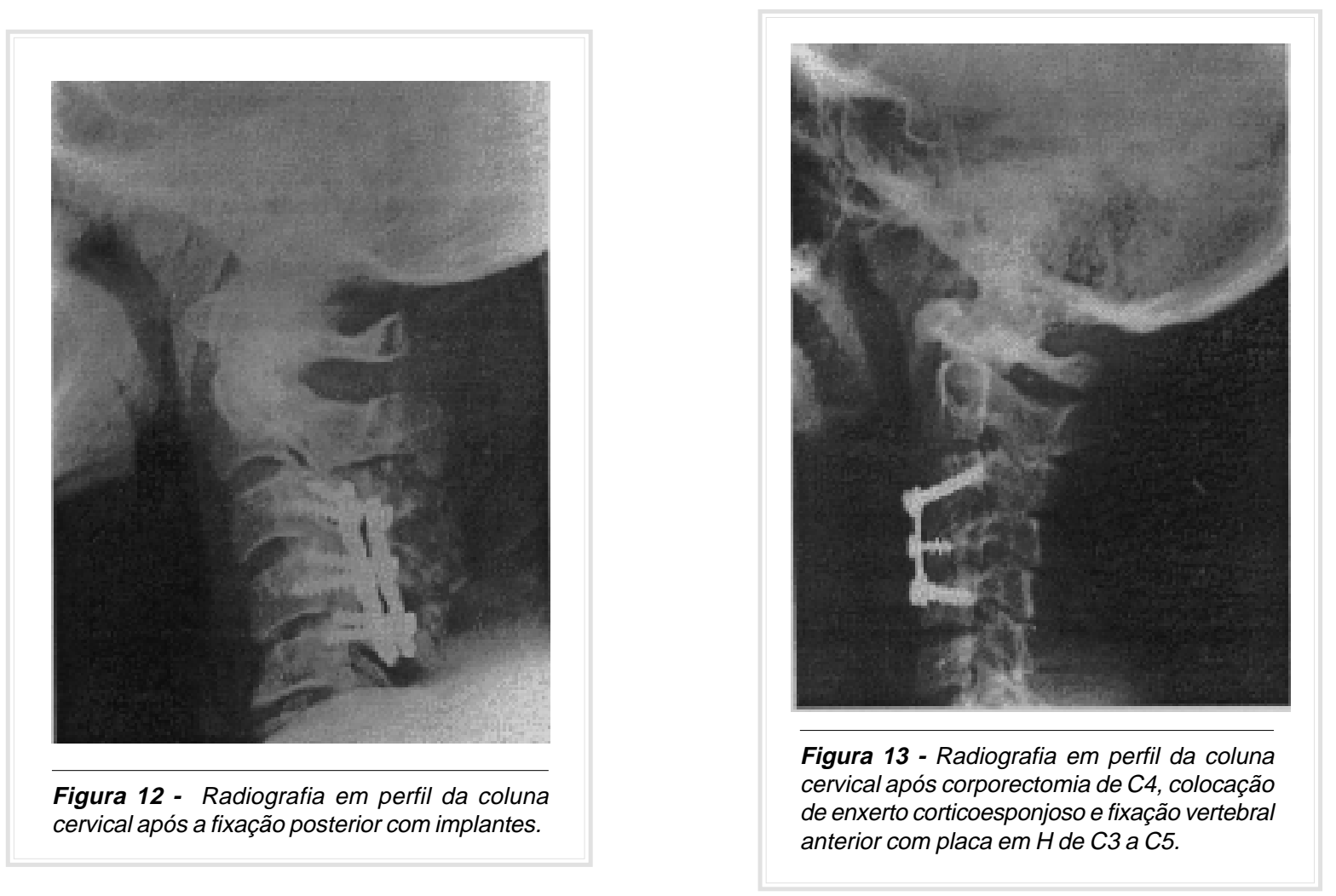

DEFINO HLA. Spinal cord injuries. Medicina, Ribeirão Preto, 32: 388-400, oct./dec. 1999.

ABSTRACT: Rachimedullary trauma (RMT) is a lesion that predominates among young adult males. Because of the characteristics of its etiology, it can be effectively prevented by means of educational campaigns directed at the population and by the adoption of individual or collective safety measures.

The therapeutic approach to RMT should be multidisciplinary from the time of patient's rescue and removal to the final rehabilitation phase.

Thus far there is no effective treatment capable of restoring the functions of the injured spinal cord. Treatment consists of patient rehabilitation and therefore all efforts should be directed at preventing this irreversible type of injury.

UNITERMS: Spinal Cord Injuries. Spinal Injuries. 


\section{REFERÊNCIAS BIBLIOGRÁFICAS}

1 - MÜLLER EJ \& MUHR G. Wirbelsäulenverletzungen. Thieme, Sttutgart, p. 124-148,1997.

2 - GREVE JM. Traumatismos raquimedulares nos acidentes de trânsito e uso de equipamentos de segurança. Diagn \& Trat 2: 10-13, 1997.

3 - BRIDWELL K \& DE WALD RL. The textbook of spinal surgery, $2^{\text {nd }}$ ed, Lippincott-Raven, Philadelphia, 1996, 2391 p.

4 - KADURIN CL. Traumatismo raquimedular por mergulho em água rasa. Proposta de um programa de prevenção. Dissertação de Mestrado, Faculdade de Medicina de Ribeirão Preto da USP, Ribeirão Preto, p. 1- 125, 1998.

5 - SLUCKY AV \& EISMONT FJ. Treatment of acute injury of the cervical spine. J Bone Joint Surg 76-A: 1882-1889, 1994.

6 - BUNGE RP; PUCKETT WR \& BECERRA JL. Observations on the pathology of human spinal cord injury: A review and classification of 22 new cases with defiles in from a case of chronic cord compression with extensive focal demyelination. Adv Neurol 59: 75-89, 1993.

7 - KAKULAS BA. Pathology of spinal injuries. Central Nervous System. Trauma 1: 117-129, 1985.
8 - BALENTINE JD; HOGANH EL \& BANIK NL. Calcium and the pathogenesis of spinal cord injuries. In: DACEY RG JR ; WINN HR \& RIMEL RW, eds. Trauma of the central nervous system. Raven Press, New York, p. 297-308, 1985.

9 - HALL ED \& BRAUGLER JM. Glucocorticoid mechanism in acute spinal cord injury: A review and therapeutic rationale. Surg Neurol 18: 320-327, 1982.

10 - BOHLMAN H H. Acute fractures and dislocations of the spine: an analysis of three hundred hospitalized patients and review of the literature. J Bone Joint Surg 61-A: 1119-1122, 1979.

11 - FRANKEL HL; HANCOCK DO; HYSLOPH G; MEZLACK J; MICHAELIS LS; UNGER GH; VERNON DS \& WALSH JJ. The value of postural reduction in the initial management of closed injuries of the spine with paraplegia and tetraplegia. Paraplegia 7: 179-185, 1969.

12 - POST MJ \& GREEN BA. The use of computed tomography in spina trauma. Radiol Clin North Am 21: 327-375, 1983.

Recebido para publicação em 08/12/1999

Aprovado para publicação em 19/01/2000 